\title{
The Adsorption Efficiency of Chemically Prepared Activated Carbon from Cola Nut Shells by $\mathrm{ZnCl}_{2}$ on Methylene Blue
}

\author{
Julius Ndi Nsami and Joseph Ketcha Mbadcam \\ University of Yaoundé I, Physical and Theoretical Chemistry Laboratory, Department of Inorganic Chemistry, \\ Faculty of Science, P.O. Box 812, Yaoundé, Cameroon \\ Correspondence should be addressed to Joseph Ketcha Mbadcam; jketcha@yahoo.com
}

Received 20 March 2013; Accepted 22 May 2013

Academic Editor: Yajing Shen

Copyright (c) 2013 J. Ndi Nsami and J. Ketcha Mbadcam. This is an open access article distributed under the Creative Commons Attribution License, which permits unrestricted use, distribution, and reproduction in any medium, provided the original work is properly cited.

\begin{abstract}
The adsorption of methylene blue from aqueous solution onto activated carbon prepared from cola nut shell has been investigated under batch mode. The influence of major parameters governing the efficiency of the process such as, solution $\mathrm{pH}$, sorbent dose, initial concentration, and contact time on the removal process was investigated. The time-dependent experimental studies showed that the adsorption quantity of methylene blue increases with initial concentration and decreasing adsorbent dosage. The equilibrium time of $180 \mathrm{~min}$ was observed and maximum adsorption was favoured at $\mathrm{pH} 3.5$. The dye removal using $0.1 \mathrm{~g}$ of adsorbent was more than $90 \%$. This dosage $(0.1 \mathrm{~g})$ was considered as the optimum dosage to remove methylene blue from aqueous solutions. The equilibrium adsorption data were analyzed by the Freundlich, Langmuir adsorption isotherm models. The kinetics of methylene blue solution was discussed by pseudo-first-order, pseudo-second-order, and Elovich models. The adsorption process follows the Elovich rate kinetic model, having a correlation coefficient in the range between 0.9811 and 1.
\end{abstract}

\section{Introduction}

Effluent from textile, dying, cosmetics, food processing, and paper making industries is polluted by dye stuff materials which of course are transported to streams which support life in our mother planet. But, anthropogenic activities have caused a great harm to the quality of our lifeline, that is, water. Because of fast depletion of the freshwater resources, the removal of dye from wastewater, particularly, by activated carbon has been reported widely. However, a survey of literature revealed that methylene blue has been used particularly for adsorption studies, not only because of its environmental concern but also for the fact that it has been recognized as a model adsorbate for the removal of organics as a result of its known strong adsorption to activated carbons [1].

Discharge of these coloured effluents presents a major environmental problem for developing countries because of their toxic and carcinogenic effects on living beings [2].
The presence of methylene blue in water system is unacceptable and even visible at concentrations as low as 1 ppm thereby affecting the aquatic systems. It also inhibits sunlight diffusion into the water, consequently reducing the photosynthetic process of aquatic plants [3]. Hence, the remediation of methylene blue from effluents before discharge into the water environment is essential. There are many methods used for the treatment procedures among which are chemical precipitation, filtration, ion exchange, reverse osmosis, ultrafiltration, electrochemical deposition, and coagulation. These methods differ in their efficiency to remove the dyes and also in the cost. However adsorption remains the outmost process because of its simplicity, high efficiency, easy recovery, and so forth [4]. Many adsorbent have been applied for the removal of methylene blue [5-11].

In 2003, it has been reported that the consumption of activated carbon risen up to about 500300 tones (five hundred thousand three hundred tones) and that $7 \%$ increase shall be felt annually [5]. 
TABLE 1: Summary of the BET $\left(\mathrm{m}^{2} / \mathrm{g}\right)$, pore volume $\left(\mathrm{cm}^{3} / \mathrm{g}\right)$, pore size $(\AA)$ and surface aspect of the chemically prepared activated carbon by $\mathrm{ZnCl}_{2}$ from cola nut shells.

\begin{tabular}{|c|c|c|c|c|}
\hline Adsorbent & $\mathrm{BET}\left(\mathrm{m}^{2} / \mathrm{g}\right)$ & Pore volume & Pore size $(\AA)$ & Surface aspect \\
\hline \multirow{3}{*}{$\mathrm{AC}$} & $\begin{array}{l}\text { Surface area at } p / p^{\circ}= \\
0.206156171: \mathbf{6 6 3 . 6 5 7 3} \mathrm{m}^{2} / \mathrm{g} \\
\text { BET Surface Area: } \mathbf{6 4 7 . 7 3 7 4} \mathrm{m}^{2} / \mathrm{g}\end{array}$ & $\begin{array}{l}\text { Adsorption total pore volume of } \\
\text { pores } 0.332061 \mathrm{~cm}^{3} / \mathrm{g}\end{array}$ & $\begin{array}{l}\text { Adsorption average pore width } \\
(4 \mathrm{~V} / \mathrm{A} \text { by BET): } \mathbf{2 0 . 5 0 5 9} \AA\end{array}$ & \multirow{3}{*}{$\begin{array}{l}\text { Heterogeneous } \\
\text { with micropores } \\
\text { and mesopores }\end{array}$} \\
\hline & $\begin{array}{l}\text { Adsorption cumulative surface } \\
\text { area of pores } 86.433 \mathrm{~m}^{2} / \mathrm{g}\end{array}$ & $\begin{array}{l}\text { Adsorption cumulative volume of } \\
\text { pores } 0.082139 \mathrm{~cm}^{3} / \mathrm{g}\end{array}$ & $\begin{array}{l}\text { Adsorption average pore } \\
\text { diameter ( } 4 \mathrm{~V} / \mathrm{A}): \mathbf{3 8 . 0 1 3} \AA\end{array}$ & \\
\hline & $\begin{array}{l}\text { Desorption cumulative surface } \\
\text { area of pores } 93.3700 \mathrm{~m}^{2} / \mathrm{g}\end{array}$ & $\begin{array}{l}\text { Desorption cumulative volume of } \\
\text { pores } \mathbf{0 . 0 8 2 8 2 7} \mathrm{cm}^{3} / \mathrm{g}\end{array}$ & $\begin{array}{l}\text { Desorption average pore } \\
\text { diameter ( } 4 \mathrm{~V} / \mathrm{A}): \mathbf{3 5 . 4 8 3} \AA\end{array}$ & \\
\hline
\end{tabular}

Since activated carbon is very expensive and efficient, it makes adsorption process more costly. As a result, low-cost and readily available alternative lignocellulosic materials are in need, while methods of production are developed.

Biomass waste including corn cob, coconut shell, palm shell, apple pulp, chickpea husks, grain sorghum, pistachio nut shell, olive stones and walnut shell, cherry stones, wild rose seeds, rice bran, oil palm shell, rubber tree seed coat, cotton stalk, tea waste, sugarcane bagasse, and empty oil palm fruit bunches has been found to be suitable precursors owing to their high-carbon and low-ash contents [12]. Chemical activation of activated carbon has been reported as more advantageous over physical activation due to higher yields, more surface area, and better development of porous structures in carbon [12].

In this research, a local agricultural waste, cola nut shells, was used to produce activated carbon. This is due to the availability and cost-free of the material with high-carbon and low inorganic content. Moreover, little or no work has been reported on the production of activated carbon using cola nut shells.

Several authors have studied the carbonization of lignocellulosic materials $[13,14]$ and found that the main degradation takes place, between $200-350^{\circ} \mathrm{C}$, with evolution of $\mathrm{H}_{2} \mathrm{O}, \mathrm{CO}, \mathrm{CO}_{2}, \mathrm{CH}_{4}$, aldehydes, and so forth. Distillation of heavier hydrocarbons (tar) takes place in the range 350$500^{\circ} \mathrm{C}$, and above $500^{\circ} \mathrm{C}$, there is little weight loss, thus indicating that the basic structure of the char has already been formed.

There is a contraction in dimensions of the lignocellulosic precursor during the carbonization process. This change in dimension is important in chemical activations, as the reagent has to be incorporated into the interior of the particles where it inhibits the expected contraction with increasing temperature which implies that the reagent may act as a template for the creation of microporosity [15]. This analysis of the porosity development allows for a comparison of methods of activation of each reagent.

Of the many reagents proposed for chemical activation, (zinc chloride, phosphoric acid, aluminium chloride, magnesium chloride, potassium hydroxide, sodium hydroxide, etc.), the most commonly used, industrially, are $\mathrm{ZnCl}_{2}, \mathrm{H}_{3} \mathrm{PO}_{4}$, and $\mathrm{KOH}$. However, the effects of $\mathrm{ZnCl}_{2}$ on activation of carbonaceous materials have been of particular interest. Also the effects of this chemical on a single precursor have not been thoroughly investigated in the literature, and the information published is limited, but activated carbon with high specific surface area using $\mathrm{ZnCl}_{2}$ as activating agent has been reported. $\mathrm{ZnCl}_{2}$ known as Lewis acid is a strong dehydrating agent which could alter the structure of carbon to form the porous structure [16].

The aim of this work was to study the adsorption efficiency of the prepared activated carbon from cola nut shells on the removal of methylene blue dye from aqueous solution.

\section{Experimental Methods}

\subsection{Treatment of Adsorbents}

2.1.1. Cola Nut Shells. Cola nut shells were initially washed with deionised water, sun dried, and grained mechanically using a grinding machine (RETSCH) then screened through a sieve (Retsch) to get geometrical size of $\leq 1.5 \mathrm{~mm}$, which by the use of a beaker was kept into an oven at $110^{\circ} \mathrm{C}$ for a period of 24 hours, removed, and cooled in a dessicator containing $\mathrm{CaCl}_{2}$ (drying agent) for $30 \mathrm{~min}$. The lignocellulosic material was removed from the dessicator, and a 1:1 mass reagent ratio was applied, mixed, and dried for 24 hours at $110^{\circ} \mathrm{C}$.

2.2. Carbon. Carbonization and activation were accomplished in a single step by carrying out thermal decomposition of the raw material (cola nut shells) impregnated with $\mathrm{ZnCl}_{2}$ as activating agent in an inert atmosphere or in the absence of oxygen in a carbolite furnace at $500^{\circ} \mathrm{C}$ for 1 hour as resident time. After activation, the furnace was allowed to cool to room temperature. The pyrolysed carbons were leached with $1 \% \mathrm{HCl}(\mathrm{v} / \mathrm{v})$ for 2-3 hours and washed several times with distilled water until a neutral $\mathrm{pH}$ was achieved. Later the carbon paste was dried in an oven at $110^{\circ} \mathrm{C}$ for at least 24 hours before application.

2.3. Chemical Reagents. Laboratory grade methylene blue (MB), a cationic dye having molecular formula of $\mathrm{C}_{16} \mathrm{H}_{18} \mathrm{~N}_{3} \mathrm{SCl}$ supplied in powder form by Merck, was used without further purification for the preparation of synthetic aqueous solution.

\section{Preparation of Solutions}

3.1. Methylene Blue Solution. All the experiments were conducted with artificial wastewater stock solution prepared by 
<smiles>CN(C)c1ccc2nc3ccc(N(C)C)cc3[s+]c2c1</smiles>

FIgURE 1: The structure of methylene blue (MB).

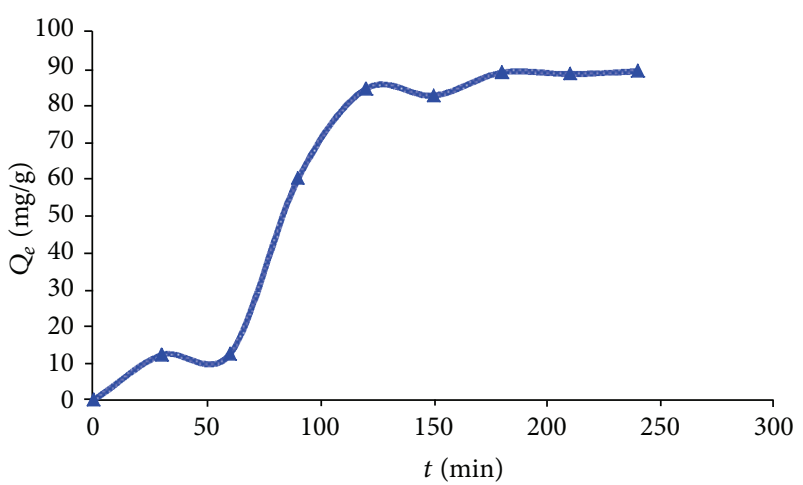

FIGURE 2: The effects of contact time on sorbent-sorbate interaction time.

dissolving analytical grade of methylene blue in distilled water.

The chemical formula of methylene blue is shown in Figure 1 [17].

A stock solution of methylene blue of concentration $500 \mathrm{ppm}(500 \mathrm{mg} / \mathrm{L})$ was prepared by dissolving $(0.5000 \pm$ $0.0001) \mathrm{g}$ of methylene blue in a $1000 \mathrm{~mL}$ volumetric flask, agitated by using a magnetic stirrer for a period of time and completed with distilled water up to the mark. This solution was again stirred with a magnetic stirrer for two hours to obtain homogeneity. Solutions of various concentrations were obtained by dilution. Solution of hydrochloric acid $(0.1 \mathrm{M})$ and sodium hydroxide $(0.1 \mathrm{M})$ was also prepared for $\mathrm{pH}$ adjustments.

3.2. The Batch Adsorption Study. The batch experiments of the adsorption studies were conducted at room temperature $\left(25^{\circ} \mathrm{C}\right)$ in a $250 \mathrm{~mL}$ screw-cap conical flask. For each run, $0.1-0.5 \mathrm{~g}$ of the adsorbent dosage was weighed and placed in the flask containing $30 \mathrm{~mL}$ solution of methylene blue of a desired concentration (ranging from 50 to $300 \mathrm{ppm}$ ), $\mathrm{pH}$ between 2 and 8 . The suspension was stirred for interval of time between 10-240 min, using a magnetic agitator and stirrer at a controllable speed. After agitation, the suspensions were filtered using Whatman no. 1 filter paper. The concentration of the filtrate was determined by using a UVvisible spectrophotometer. The absorbance was measured at the maximum absorption wavelength of $668 \mathrm{~nm}$.

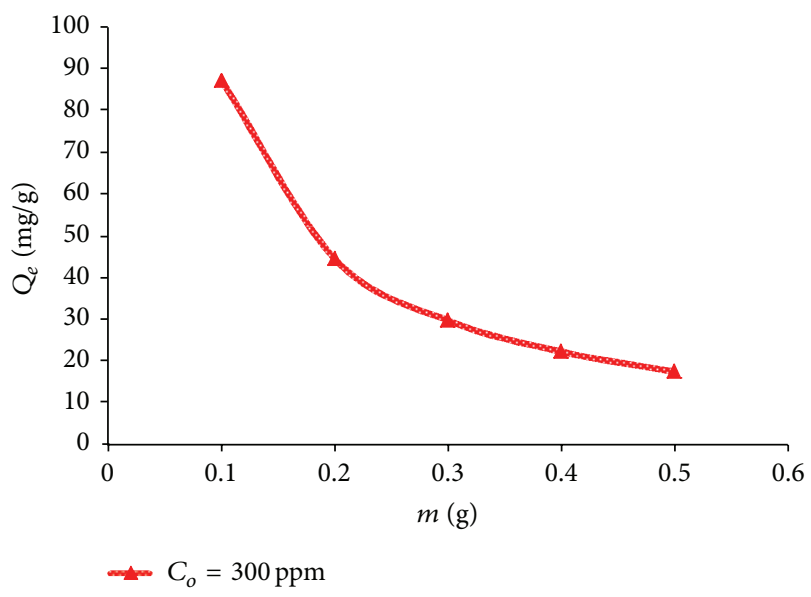

FIGURE 3: The effect of carbon dose for the uptake of methylene blue.

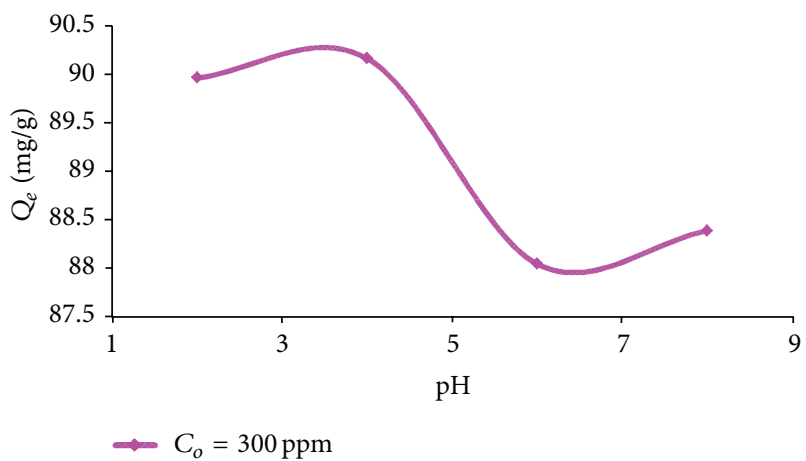

Figure 4: The effect of $\mathrm{pH}$ on methylene blue adsorption by activated carbon prepared from cola nut shells by chemical activation with $\mathrm{ZnCl}_{2}$.

The quantity adsorbed by a unit mass of an adsorbent at equilibrium $\left(Q_{e}\right)$ and the adsorption percentage $(\% R)$ at an instant were calculated using the relations (1), respectively,

$$
\begin{aligned}
Q_{e} & =\frac{C_{o}-C_{t}}{m} V, \\
\% R & =\frac{C_{o}-C_{t}}{C_{o}} 100,
\end{aligned}
$$

where $C_{e}$ is the concentration of adsorbate at equilibrium; $C_{t}$ is the concentration of adsorbate at time $t ; C_{o}$ is the initial concentration; $m$ is the mass of the adsorbent; and $V$ is the volume of the adsorbate.

\section{Results and Discussion}

4.1. The Characteristics of Activated Carbon Obtained from Cola Nut Shells. Table 1 summarizes the characteristics of activated carbon prepared from cola nut shells.

It can be seen that the nature of the prepared activated carbon consisting mainly of mesopores which are very favourable for adsorption of large molecules like methylene 


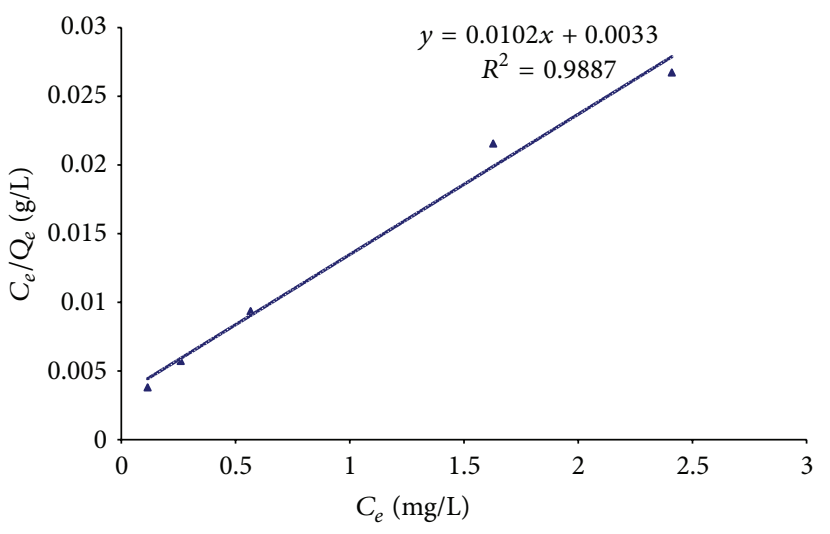

(a)

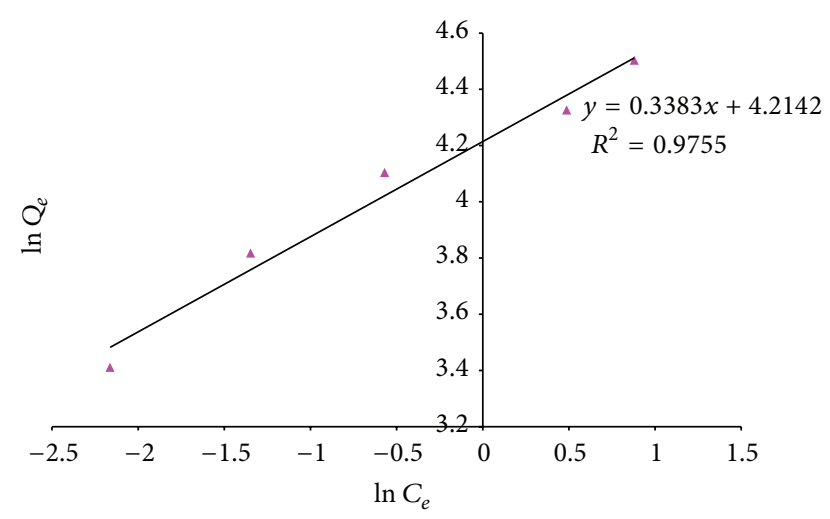

(b)

FIgURE 5: The linear plots, (a) from Langmuir adsorption model and (b) from Freundlich adsorption model.

blue with an average recommended, significant surface area between $500-1500 \mathrm{~m}^{2} / \mathrm{g}$, reported by Chand and Bansal [18] in his book, that widely used activated carbon adsorbents has specific surface area on the order 500 to $1500 \mathrm{~m}^{2} / \mathrm{g}$ and pore volume on the order of 0.20 to $0.60 \mathrm{~cm}^{3} / \mathrm{g}$.

4.2. Adsorption Contact Time Test. Methylene blue adsorption on activated carbon prepared from cola nut shells increases with increasing agitation time as shown in Figure 2.

The removal rate was slow within the first 50 min then increases rapidly and gradually diminished to attain equilibrium within $180 \mathrm{~min}$ beyond which there was no significant increase in the removal rate. It is thought that the first step leads to surface adsorption and the second step leads to intraparticle transport from bulk fluid to the external surface of the porous adsorbent [19]. This trend agrees with the report of other investigators [20]. The stages of sorption of methylene blue on activated carbon might be controlled by the diffusion process from bulk to the surface or the heterogeneous nature of the adsorbent.

4.3. Effect of Carbon Dose. In order to study the effect of adsorbent dosage on the adsorption of methylene blue, a series of adsorption experiments were carried out with different adsorption dosages varying from 0.1 to $0.5 \mathrm{~g}$ at initial concentration of $100 \mathrm{ppm}$.

The effect of carbon dose for the uptake of methylene blue by activated carbon from cola nut shells was found to decrease by increasing the adsorbent dose. This may be allocated to the fact that as the amount in grams of adsorbent is increased the total surface area available for the adsorption of methylene blue reduces as a result of overlapping or aggregation of adsorption sites [21]. Furthermore, maximum quantity adsorbed, $Q_{e}=87.37 \mathrm{mg} / \mathrm{g}$, was reached by $0.1 \mathrm{~g}$ activated carbon prepared from agricultural waste (cola nut shells, see Figure 3).

4.4. Effect of $p H$ Experiments. To study the effect of $\mathrm{pH}$ on methylene blue (MB) adsorption, $0.1 \mathrm{~g}$ of activated carbon was added to solutions containing $300 \mathrm{ppm}$ of methylene blue ions. The initial $\mathrm{pH}$ values were adjusted from 2-8 using $0.1 \mathrm{M} \mathrm{HCl}$ and $0.1 \mathrm{M} \mathrm{NaOH}$. After the suspensions were shaken for $180 \mathrm{~min}$, equilibrium time, at room temperature, they were filtered using Whattman no. 1 filter paper and analyzed for residual methylene blue concentration.

Figure 4 shows higher adsorption of methylene blue at low $\mathrm{pH}=3.5$ which is due to increased protonation by neutralization of the negative charges at the surface of adsorbent. But for $\mathrm{pH}<3.5$, the number of negatively charged adsorbent sites decreased and the number of positively charged surface sites increased, which did not favour the adsorption of positively charged dye cation due to electrostatic repulsion. In addition, lower adsorption of methylene blue at acidic $\mathrm{pH}$ might be due to the presence of excess $\mathrm{H}^{+}$ions competing with dye cations for the available adsorption sites. For $\mathrm{pH}$ values higher than 7 , the amount of dye removal started to increase, and in this case, may be in alkaline solutions, methylene blue might have stepwise, demethylated to other common dyes [7]. This indicated that the adsorption capacity of activated carbon prepared from cola nut shells was $\mathrm{pH}$ dependent.

\section{Adsorption Isotherms and Kinetic Models}

5.1. Adsorption Isotherm Models. An adsorption isotherm is the relationship between the adsorbate in the liquid phase and the adsorbate adsorbed on the surface of the adsorbent at equilibrium at constant temperature. In order to successfully represent the dynamic adsorptive behavior of any substances from the fluid to the solid phase, it is important to have a satisfactory description of the equilibrium state between the two phases composing the adsorption system. The Langmuir and Freundlich isotherms are the two most well-known isotherms which have been used to describe the equilibrium of adsorption systems.

5.2. The Langmuir Adsorption Isotherm. The Langmuir isotherm takes an assumption that adsorption occurs at 


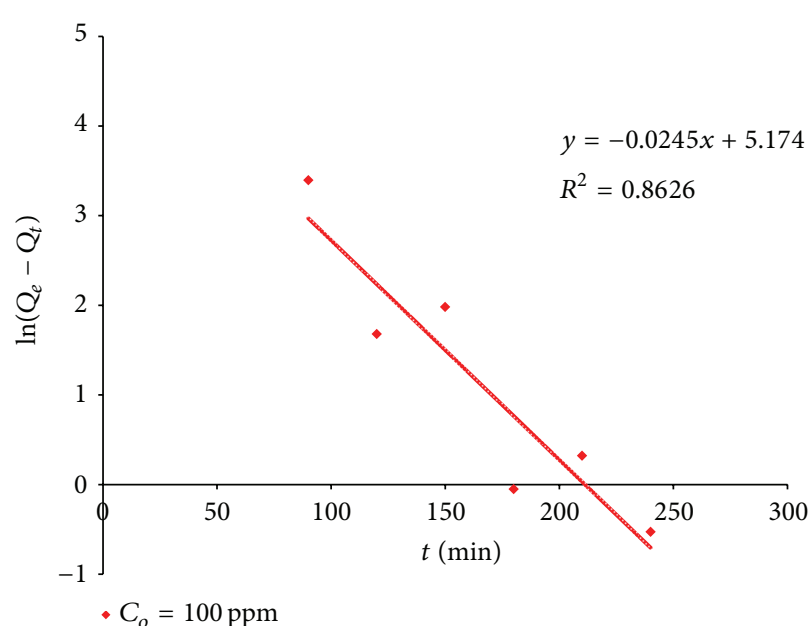

(a)

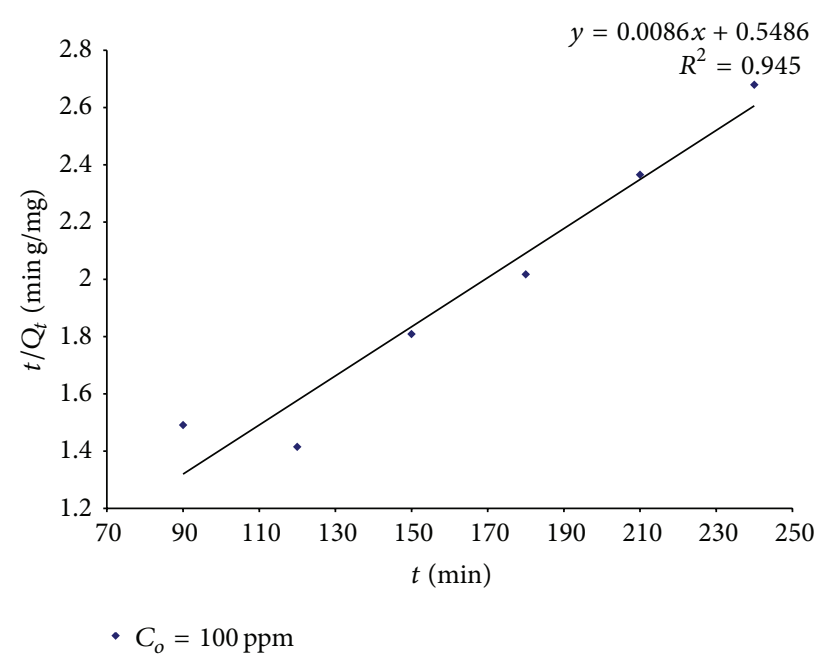

(b)

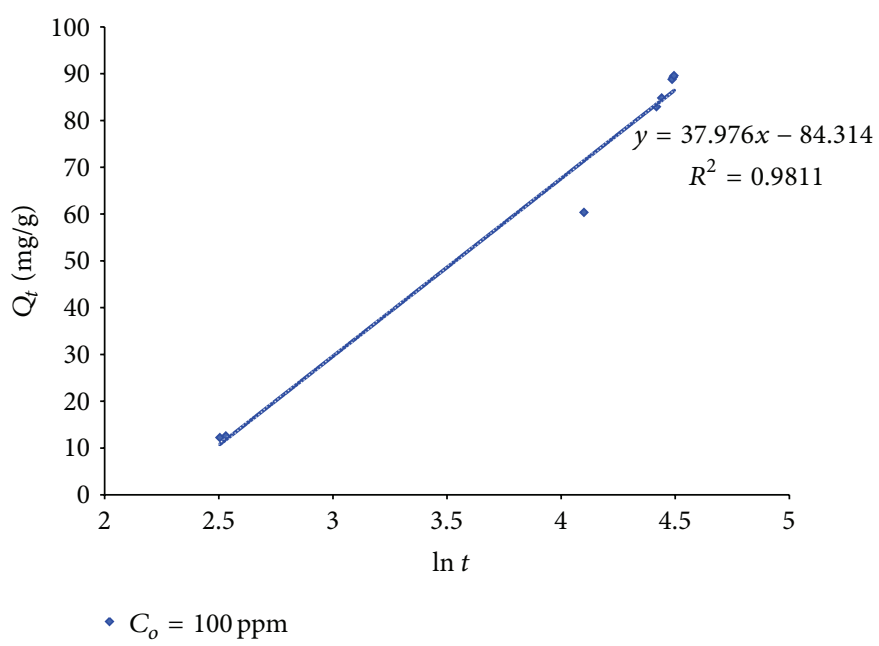

(c)

FiguRE 6: The linear plots, (a) pseudo-first-order and (b) pseudo-second-order, (c) Elovich kinetic models for the adsorption of methylene blue onto activated carbon prepared from kola nut shells.

specific homogeneous sites within the adsorbent. The equation is as follows:

$$
Q_{e}=\frac{Q_{m} K C_{e}}{1+K C_{e}}
$$

where $Q_{e}$ (mg of adsorbate per g of adsorbent) is the adsorption density at the equilibrium solute concentration $C_{e}$. $C_{e}$ is the equilibrium concentration of adsorbate in solution (mg/L). $Q_{m}$ (mg of solute adsorbed per $g$ of adsorbent) is the maximum adsorption capacity corresponding to complete monolayer coverage.

$K$ is the Langmuir constant related to energy of the adsorption ( $L$ of adsorbate per mg of adsorbent).

The previous equation can be rearranged to the following linear form:

$$
\frac{C_{e}}{Q_{e}}=\frac{1}{Q_{m} K}+\frac{C_{e}}{Q_{m}}
$$

The linear form can be used for linearization of experimental data by plotting $C_{e} / Q_{e}$ against $C_{e}$. The Langmuir constants $Q_{m}$ and $K$ can be evaluated from the slope and intercept of the linear equation:

$$
Q_{e}=\frac{Q_{m} K C_{e}}{1+K C_{e}}
$$

where $Q_{e}$ (mg of adsorbate per $\mathrm{g}$ of adsorbent) is the adsorption density at the equilibrium solute concentration $C_{e} . C_{e}$ is the equilibrium concentration of adsorbate in solution $(\mathrm{mg} / \mathrm{L})$.

$Q_{m}$ (mg of solute adsorbed per $g$ of adsorbent) is the maximum adsorption capacity corresponding to complete monolayer coverage.

$K$ is the Langmuir constant related to energy of the adsorption ( $L$ of adsorbate per $\mathrm{mg}$ of adsorbent). 
TABLE 2: Parameter values of the isotherms adsorption of methylene blue onto activated carbon from cola nut shells.

\begin{tabular}{lcccccc}
\hline & Equation & $R^{2}$ & $Q_{e}$ & $Q_{m}$ & $K_{L}$ & $K_{F}$ \\
\hline Langmuir & $y=0.0102 x+0.0033$ & 0.9887 & 89.22 & 87.12 & 3.48 & $/ / n$ \\
Freundlich & $y=0.3383 x+4.2142$ & 0.9755 & $/$ & $/$ & $/$ & 67.64 \\
\hline
\end{tabular}

TABLE 3: Parameter values of the kinetic studies of the adsorption of methylene blue onto activated carbon from cola nut shells.

\begin{tabular}{lccccc}
\hline & \multicolumn{1}{c}{ Equation } & $R^{2}$ & $K_{1}$ & $K_{2}$ & $\alpha$ \\
\hline Pseudo-first-order & $y=-0.0245 x+5.174$ & 0.8626 & 0.0232 & $/$ & $/$ \\
Pseudo-second-order & $y=0.0086 x+0.5486$ & 0.945 & $/$ & 0.0198 & $/$ \\
Elovich & $y=37.976 x-84.314$ & 0.9811 & $/$ & $/$ & 4.44 \\
\hline
\end{tabular}

The previous equation can be rearranged to the following linear form:

$$
\frac{C_{e}}{Q_{e}}=\frac{1}{Q_{m} K}+\frac{C_{e}}{Q_{m}}
$$

The linear form can be used for linearization of experimental data by plotting $C_{e} / Q_{e}$ against $C_{e}$. The Langmuir constants $Q_{m}$ and $K$ can be evaluated from the slope and intercept of the linear equation.

5.3. The Freundlich adsorption Isotherm. The Freundlich isotherm is an empirical equation employed to describe the heterogeneous system (16). The equation is given below:

$$
Q_{e}=K_{f} C_{e}^{1 / n} \text {, }
$$

where $Q_{e}$ is the quantity of solute adsorbed at equilibrium (adsorption density: $\mathrm{mg}$ of adsorbate per $\mathrm{g}$ of adsorbent). $C_{e}$ is the concentration of adsorbate at equilibrium, where $K_{f}$ and $1 / n$ are empirical constants dependent on the nature of sorbent and sorbate and the temperature. Both of these values $\left(K_{f}\right.$ and $\left.1 / n\right)$ are important in selecting an adsorbent as a separating medium, in which $K_{f}(\mathrm{mg} / \mathrm{g})$ is the over-all adsorption capacity $\left(Q_{e}\right.$ at $C_{e}=1 \mathrm{mg} / \mathrm{L}$ or $\left.\log C_{e}=0\right)$ and $1 / n$ is the heterogeneity factor. The heterogeneity factor $1 / n$ indicates the strength of bond energy between sorbate and sorbent.

This equation is conveniently used in linear form by taking the logarithmic of both sides as

$$
\ln Q_{e}=\ln K_{f}+\frac{1}{n} \ln C_{e}
$$

A plot of $\ln Q_{e}$ against $\ln C_{e}$ yielding a straight line indicates the confirmation of the Freundlich isotherm for adsorption. The constants can be determined from the slope and the intercept.

From Figure 5, the adsorption isotherm of methylene blue shows that the data both fitted Langmuir and Freundlich isotherms but fitted better in Langmuir isotherm equation by comparing the $R^{2}$ values of Langmuir and Freundlich isotherm as shown in Table 2.

This implies that a monolayer sorption proceeds over a surface containing a finite number of adsorption sites and uniform strategies of adsorption with no transmigration of adsorbate in the plane of surface. In the literature, several authors reported the difficulties of comparing adsorption intensities, due to lack of consistencies in data. $1 / n$, which is a measure of surface heterogeneity, is also a measure of adsorption intensities. Adsorption on the surface becomes more heterogeneous as $1 / n$ values get closer to zero. From Table $1,1 / n<1$ shows normal adsorption [22].

5.4. Kinetic Adsorption Models. In the present research, the kinetics of adsorption of methylene blue on the activated carbon prepared from cola nut shells by chemical modification by $\mathrm{ZnCl}_{2}$ was studied. Three types of kinetic models, pseudo-first-order (Lagergren equation), pseudo-secondorder model (Ho equation), and Elovich model [6], were employed to fit experimental data (Figure 6).

The straight lines plots showed a good agreement of experimental data with pseudo-second-order model and Elovich model. Table 3 listed the results of rate constant studies for different kinetic models. Comparing the $R^{2}$ values, pseudo-second-order and Elovich models show a significant agreement with adsorption mechanisms being the two, with successfulness of the Elovich model. The general explanations for this form of kinetic equation involve a variation of the energetic of chemisorption with the heterogeneous active sites in activated carbon. This supports that the heterogeneous sorption mechanism is likely to be responsible for the methylene blue uptake. Elovich model basically supports chemisorption [23].

\section{Conclusion}

This study confirmed that the activated carbon prepared from a low-cost agricultural waste (cola nut shells) could effectively remove methylene blue from an aqueous solution with the optimal $\mathrm{pH}$ for favourable adsorption of methylene blue equal to 3.5. The adsorbent dosage had an effect on the adsorption process of methylene blue. The adsorption equilibrium was reached in $180 \mathrm{~min}$ with the isothermal data fitted well in Langmuir model and Freundlich model indicating a chemisorption adsorption. Also the adsorption process followed Elovich rate kinetic model. 


\section{Acknowledgments}

This work was conducted as part of a Ph.D. degree thesis research work at the University of Yaoundé I in the Physical and Theoretical Chemistry laboratory. The authors are grateful to Professor Marc Cretin, institut Europeen des Membranes of the University of Montpellier II, France, in recording BET results. The authors also thank all the members of the research group "Adsorption and Surface" of this same laboratory.

\section{References}

[1] E. S. Abechi, C. E. Gimba, A. Uzairu, and J. A. Kagbu, "Kinetics of the adsorption of methylene blue onto activated carbon prepared from palm kernel shell," Scholar Research Library, vol. 3, no. 1, pp. 154-164, 2011.

[2] G. Unal, O. Gulce, and C. G. Gizem, "Removal of methylene blue from aqueous solution by activated carbon prepared from Pea shells (PislumSativam)," Journal of Chemistry, vol. 3, Article ID 614083, 9 pages, 2013.

[3] A. Oladayo, S. A. Olushola, O. O. Godwin, and G. Olamide, "Adsorption kinetics and intraparticulate diffusivity of Aniline blue dye onto activated plantain peels carbon," Chemical Science Transactions, vol. 2, no. 1, pp. 294-300, 2012.

[4] J. Ketcha Mbadcam, S. Anagho Gabche, J. Ndi Nsami, and A. M. Kammegne, "Kinetic and equilibrium studies of the adsorption of Lead(II) ions from aqueous solution onto two Cameroon Clays: kaolinite and smectite," Journal of Environmental Chemistry and Ecotoxicology, vol. 3, no. 11, pp. 290-297, 2011.

[5] C. E. Gimba, O. Ocholi, P. A. Egwaikhide, T. Muyiwa, and E. E. Akporhonor, "New raw material for activated carbon. I. Methylene blue adsorption on activated carbon prepared from Khaya senegalensis fruits," Ciencia e Investigacion Agraria, vol. 36, no. 1, pp. 107-114, 2009.

[6] S. Y. Darmadi Thomas, T. G. ChoongChuah, Y. H. RobiahYunus, and T. Yap, "Adsorption of methylene blue from aqueous solution on carbon coated monolith," ASEAN Journal of Chemical Engineering, vol. 8, no. 1, pp. 27-38, 2008.

[7] S. Zohre, S. Ataallah, Goharrizi, and A. Mehdi, "Experimental study of methylene blue adsorption from aqueous solutions onto carbon nano-tubes," International Journal of Water Resources and Environmental Engineering, vol. 2, no. 2, pp. 1628, 2010.

[8] V. Bello-Huitte, P. Atenco Fernandez, and R. Reyes Mazzoco, "Adsorption studies of methylene blue and phenol onto pecan of castile nutshellsprepared by chemical activation," Revista Mexicana De Ingenieria Guimica, vol. 9, no. 3, pp. 313-322, 2010.

[9] T. Santhi and S. Manonmani, "Removal of methylene blue from aqueous solution by bioadsorption onto Ricinus conmmunis epicarp activated carbon," Chemical Engineering Research Bulletin, vol. 13, pp. 1-5, 2009.

[10] E. S. Abechi, C. E. Gimba, A. Uzairu, and J. A. Kagbu, "Kinetics of adsorption of methylene blue onto activated carbon prepared from palm kernel shells," Archives of Applied Science Research, vol. 3, no. 1, pp. 154-164, 2011.

[11] H. Yuh Shan, R. Malarvizhi, and N. Sulochana, "Equilibrium isotherm studies of methylene adsorption onto activated carbon prepared from Delonixregia pods," Journal of Environmental Protection, vol. 3, pp. 111-116, 2009.

[12] P. Sugumarn, V. Priya, P. Susan Ravichandran, and S. Seshadri, "Production and characterization activated carbon from banana empty fruit brunch and delonixregia fruit pod," Journal of Sustainable Energy \& Environment, vol. 3, pp. 125-132, 2012.

[13] F. Caturla, M. MolinSabio, and F. Rodriquez Ranoso, "Preparation of Activated by chemical activation with $\mathrm{ZnCl}_{2}$," Carbon, vol. 29, article 999, 1991.

[14] J. D. . Dina Djoh, R. AbdoulNtieche, J. Ndi Nsami, and J. Ketcha Mbadcam, "Adsorption of Acetic Acid onto activated carbon obtained from maize cobs by chemical activation with Zinc Chloride $\left(\mathrm{ZnCl}_{2}\right)$," Research Journal of Chemical Sciences, vol. 2, no. 9, pp. 42-49, 2012.

[15] E. Gonzalez-Srrano, T. Cordaro, J. Rodriquez-Mirasol, and J. J. Rodriquez, "Development of porosity upon chemical activation of Kraft lignin with $\mathrm{ZnCl}_{2}$," Industrial \& Engineering Chemistry Research, vol. 36, pp. 4832-4838, 1997.

[16] A. B. M. N. Allwar and M. A. B. M. Nawi, "Textural characteristics of activated carbon prepared form oil palm shells activated with $\mathrm{ZnCl}_{2}$ and pyrolysis under nitrogen and carbon dioxide," Journal of Physical Science, vol. 19, no. 2, pp. 93-104, 2008.

[17] D. Darmadi, T. S. Y. Choong, T. G. Chuah, Y. H. RobiahYunus, and T. Yap, "Adsorption of methylene blue form aqueous solutions on carbon coated monolith," Asian Journal of Chemistry, vol. 8, no. 1, pp. 27-38, 2008.

[18] R. Chand and M. G. Bansal, Activated Carbon Adsorption, Taylor and Francis; LLC, 2005.

[19] N. Renugadevi, R. Sangeetha, and P. Lalitha, "Kinetics of the adsorption of methylene blue from an industrial dyeing effluent onto activated carbon prepared from the fruits of Mimusops Elengi," Archives of Applied Science Research, vol. 3, no. 3, pp. 492-498, 2011.

[20] E. S. Abechi, C. E. Gimba, A. Uzairu, and J. A. Kagbu, "Kinetcis of adsorption of methylene onto acctivated carbon prepared from palm kernel shell," Archives of Applied Science Research, vol. 3, no. 1, pp. 154-164, 2011.

[21] B. Das and N. K. Mondal, "Calcareous soil as a new adsorbent to remove lead from aqueous solution: equilibrium, kinetic and thermodynamic study," Universal Journal of Environmental Research and Technology, vol. 1, no. 4, pp. 515-530, 2011.

[22] A. Itodo, "Derived Low cost biosorbent as water decolourizer," Research Journal of Pharmaceutical, Biological and Chemical Sciences, vol. 2, article 693, no. 1, 2011.

[23] N. Renugadevi, R. Sangeetha, and P. Lalitha, "Kinetic of the adsorption of methylene blue from an industrial dyeing effluent onto activated carbon prepared from the fruits of Mimusops Elongi," Archives of Applied Science Research, vol. 3, no. 3, pp. 492-498, 2011. 

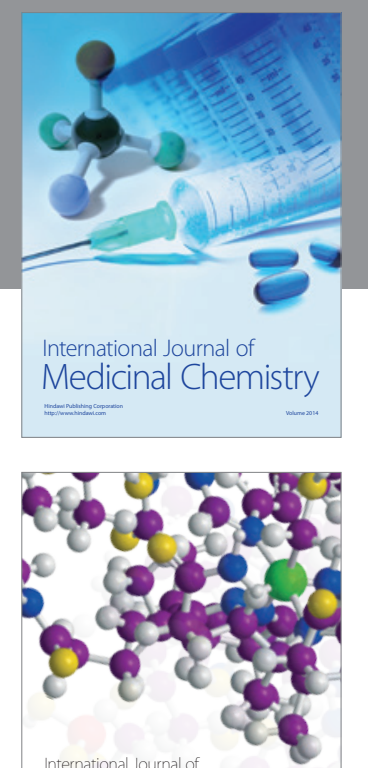

\section{Carbohydrate} Chemistry

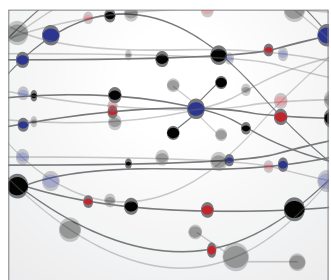

The Scientific World Journal
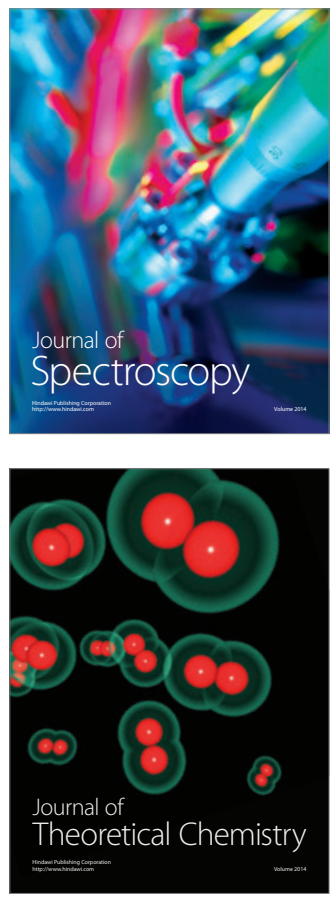
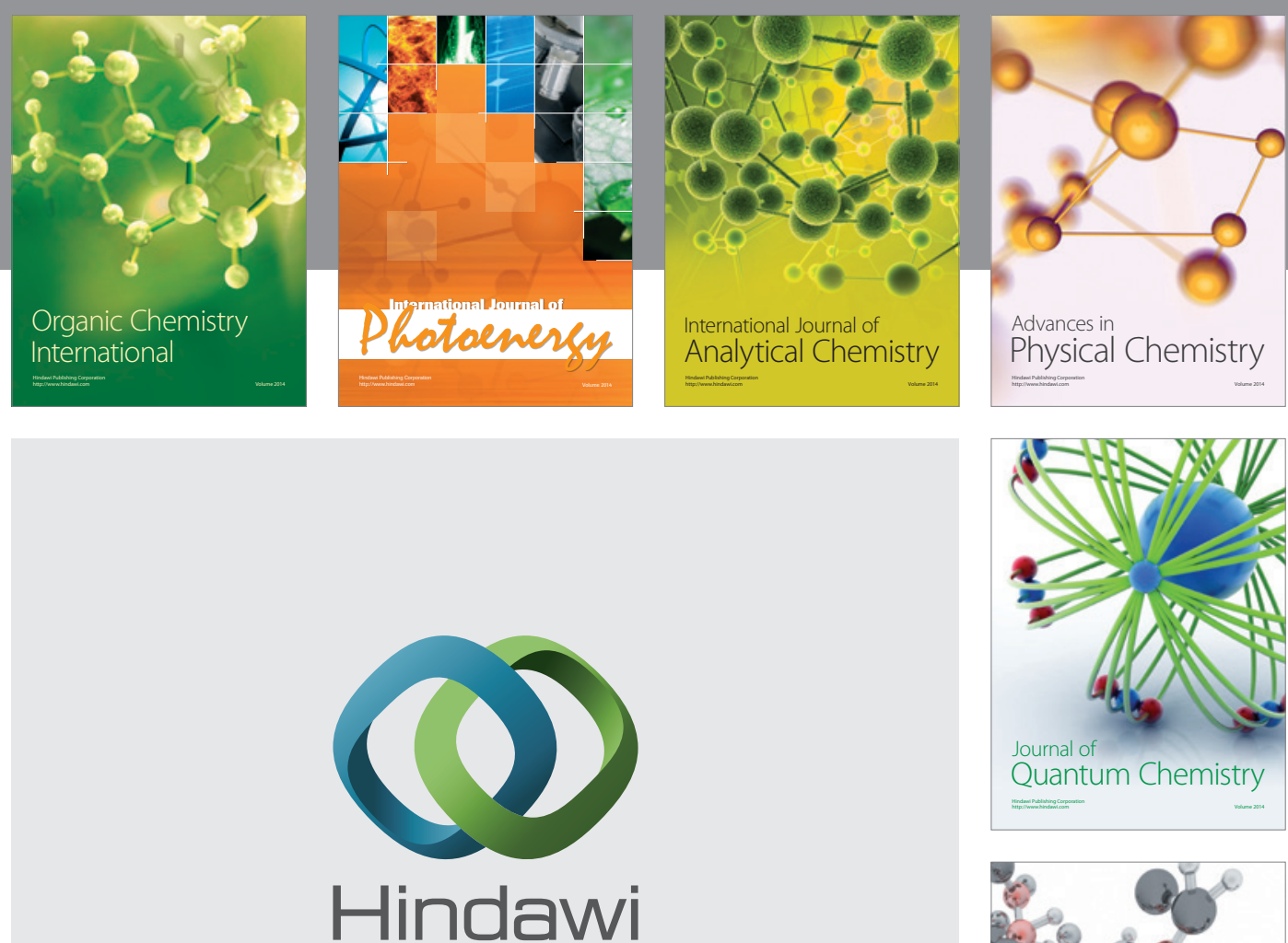

Submit your manuscripts at

http://www.hindawi.com

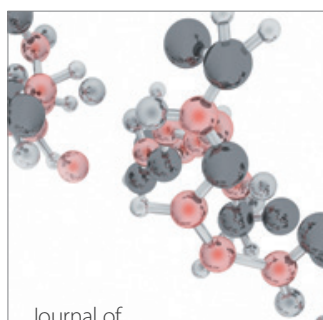

Analytical Methods

in Chemistry

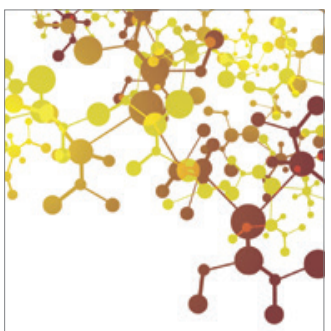

Journal of

Applied Chemistry

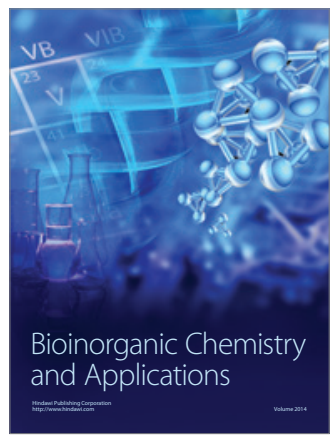

Inorganic Chemistry
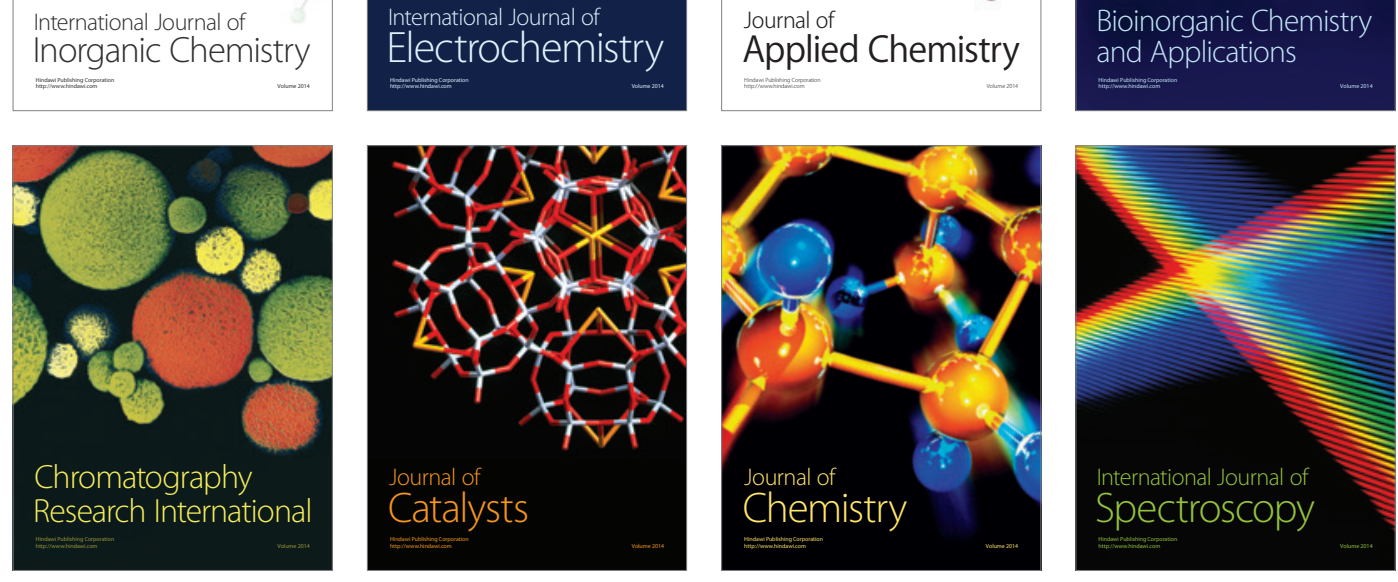